\title{
A B-cell targeting virus disrupts potentially protective genomic methylation patterns in lymphoid tissue by increasing global 5-hydroxymethylcytosine levels
}

\author{
Nick A Ciccone ${ }^{1 *}$, William Mwangi ${ }^{1}$, Alexey Ruzov ${ }^{2}$, Lorraine P Smith ${ }^{1}$, Colin Butter ${ }^{1}$ and Venugopal Nair ${ }^{1}$
}

\begin{abstract}
The mechanisms by which viruses modulate the immune system include changes in host genomic methylation. 5-hydroxymethylcytosine ( $5 \mathrm{hmC}$ ) is the catalytic product of the Tet (Ten-11 translocation) family of enzymes and may serve as an intermediate of DNA demethylation. Recent reports suggest that $5 \mathrm{hmC}$ may confer consequences on cellular events including the pathogenesis of disease; in order to explore this possibility further we investigated both 5-methylcytosine $(5 \mathrm{mC})$ and $5 \mathrm{hmC}$ levels in healthy and diseased chicken bursas of Fabricius. We discovered that embryonic B-cells have high $5 \mathrm{mC}$ content while $5 \mathrm{hmC}$ decreases during bursa development. We propose that a high $5 \mathrm{mC}$ level protects from the mutagenic activity of the B-cell antibody diversifying enzyme activation induced deaminase (AID). In support of this view, AID mRNA increases significantly within the developing bursa from embryonic to post hatch stages while mRNAs that encode Tet family members 1 and 2 reduce over the same period. Moreover, our data revealed that infectious bursal disease virus (IBDV) disrupts this genomic methylation pattern causing a global increase in $5 \mathrm{hmC}$ levels in a mechanism that may involve increased Tet 1 and 2 mRNAs. To our knowledge this is the first time that a viral infection has been observed to cause global increases in genomic $5 \mathrm{hmC}$ within infected host tissues, underlining a mechanism that may involve the induction of B-cell genomic instability and cell death to facilitate viral egress.
\end{abstract}

\section{Introduction}

Cytosines within the genome not only constitute part of the genetic code but are also amenable to chemical modification making them a central conveyer of epigenetic information. Methylation of the fifth position of cytosine (5-methylcytosine, $5 \mathrm{mC}$ ) is an evolutionarily conserved epigenetic modification [1] which helps to maintain genome stability and acts as a suppressive mark for gene expression [2]. It is becoming apparent that genomic DNA demethylation is more prevalent and dynamic than was previously appreciated. A mechanistic understanding of active DNA demethylation indicates the involvement of cytosine hydroxymethylation $(5 \mathrm{hmC})$ [3]. The Tet (Ten-11 translocation) proteins can convert $5 \mathrm{mC}$

\footnotetext{
* Correspondence: nick.ciccone@pirbright.ac.uk

${ }^{1}$ Avian Viral Diseases (AVD), Compton Laboratory, The Pirbright Institute, Compton, Berkshire RG20 7NN, UK

Full list of author information is available at the end of the article
}

to $5 \mathrm{hmC}[3,4]$ making these enzymes pivotal players in events leading to complete cytosine demethylation [5]. The finding that many tissues accumulate substantial $5 \mathrm{hmC}$ levels [6,7] allows for the intriguing possibility that this cytosine modification is not only a transient intermediate leading to complete DNA demethylation but may also be an epigenetic entity that carries its own unique coding properties and consequences.

Although the biological role of $5 \mathrm{hmC}$ and Tet proteins remain to be fully established, current models suggest their involvement in vertebrate embryonic development [8-10], while the abundance of $5 \mathrm{hmC}$ within gene bodies and enhancers has been ascribed to a role in modulating transcription [6,11]. Recent studies have observed global genomic increases in $5 \mathrm{hmC}$ in somatic tissue during aging [12] and as a characteristic feature of disease [13]. In contrast, disruptions to Tet 1 and 2 functions have been associated with reduced $5 \mathrm{hmC}$ levels in various forms of 
cancer $[7,14]$. Such examples include leukaemia which is often associated with mutations in the catalytic activity of Tet 2 leading to diminished $5 \mathrm{hmC}$ levels in hematopoietic stem cells (HSC), delayed HSC differentiation and skewed development toward a monocyte/macrophage lineage $[15,16]$. Collectively, these studies suggest that disruption to the correct regulation of genomic $5 \mathrm{hmC}$ is not only a diagnostic marker for disease but also suggests that changes in $5 \mathrm{hmC}$ levels may be part of a causal mechanism underlying the pathogenesis of multiple disorders including those of the immune system.

Viruses, being obligate intracellular parasites, have evolved several sophisticated mechanisms to hijack cellular machinery and to evade their host's immune system. Oncogenic viruses, including those that infect immune cells, are known to modulate the expression of DNA methyltransferases to silence tumor suppressor genes through promoter hypermethylation [17-20]. To our knowledge, no study has explored possible changes in host genomic $5 \mathrm{hmC}$ levels after viral infection.

As vertebrates whose embryonic stages are readily accessible to investigation, chickens have made major contributions to many areas of immunology and development [21]. It was in chickens that the existence of the bursa of Fabricius (BF) and the B-cells that specialise in antibody production within it was first described [21]. Avian B-cells are crucial for inducing antibody responses against viral pathogens; in response viruses that infect birds often target B-cells to avoid elimination [22,23]. One such pathogen of veterinary and economic significance is infectious bursal disease virus (IBDV) which infects and subsequently causes cell death of developing B-cells as part of a mechanism to avoid elimination from the host [23-25]. Chickens within a commercially produced flock can recover from IBDV infection but remain immunosuppressed due, in part, to a reduced B-cell capacity. These birds are susceptible to future pathogen infections and respond poorly to vaccination regimes to protect flocks from other viral infections of economic importance $[23,24]$. In the current study we investigated possible changes in $5 \mathrm{hmC}$ and $5 \mathrm{mC}$ patterns during the ontogeny of B-cells within the developing BF and tested the hypothesis that IBDV infection disrupts the genomic methylation patterns within this primary lymphoid organ.

\section{Materials and methods}

\section{Animals and IBDV infection}

Specific pathogen free (SPF), inbred line 0 or $15 \mathrm{~L}$ chickens and either fertilized Rhode Island Red eggs containing viable embryos or neonatal chicks were obtained from the poultry production unit at The Pirbright Institute. Both rearing and experimentations were conducted in accordance with the UK animal scientific procedures act 1986 and were approved by the Pirbright Institute internal ethical review procedure and were performed under Home Office guidelines of the United Kingdom. For experiments concerning the developing bursa of Fabricius, chicks at various embryonic stages of development or post hatch were culled and bursa were rapidly removed and stored until tissue analysis (see relevant method heading for further information). For IBDV studies, an infectious dose of virulent UK661 IBDV strain or phosphate buffered saline (PBS) alone was administered per nares in a fifty microliter volume to six-week old chickens. Birds were culled 48 hours post infection (hpi) and bursa were rapidly dissected and processed.

\section{Immunofluorescence and bioimaging}

Bursal tissue were sectioned using a cryostat (Leica CM1900, Milton Keynes, UK) set at a cutting width of $0.6 \mu \mathrm{M}$ and subsequently fixed in $4 \%$ paraformaldehyde for thirty minutes at ambient temperature. Sections were then permeabilized in 1\% Triton X100 (Sigma-Aldrich, Poole, UK) for $15 \mathrm{~min}$ at room temperature before incubation at $37{ }^{\circ} \mathrm{C}$ in either $2 \mathrm{~N}$ or $4 \mathrm{~N} \mathrm{HCl}$ (Sigma-Aldrich) for one hour. Primary antibodies were diluted in $10 \%$ fetal bovine serum (FBS) and incubated for one hour at room temperature. To detect specific genomic cytosine modifications, antibodies raised against $5 \mathrm{hmC}$ (Active Motif, La Hulpe, Belgium, 1:1000) and 5mC (33D3, Diagenode, Seraing, Belgium, 1:500) were used. While a monoclonal antibody (AV20, Southern Biotech, Birmingham, AL, USA) directed against the Bu-1 molecule was used to specifically detect B-cells. Secondary fluorescent antibodies, Alexa 568 goat anti-rabbit (Life Technologies, Paisley, UK) to visualize $5 \mathrm{hmC}$ and either Alexa 488 goat anti-mouse (Life Technologies) to detect $5 \mathrm{mC}$ or $\mathrm{Bu}-1$, were diluted 1:500 in 10\% FBS and incubated at room temperature for one hour. After washing in PBS, sections were either incubated in 4', 6-Diamidino-2phenyindole (DAPI; Sigma-Aldrich) diluted 1:10 000 in $\mathrm{dH}_{2} \mathrm{O}$ for $10 \mathrm{~min}$ at room temperature for cellular DNA conterstaining prior to mounting or mounted directly in mounting media (Vector Laboratories, Peterborough, UK). Control staining without primary antibody incubation gave either no or minimal detectable signal. Images were captured using a Leica TCS SP5 confocal microscope linked to a personal computer running LAS AF software (Leica Microsystems, Milton Keynes, UK).

\section{DNA dot blot assay}

Bursal tissue were placed in $2.0 \mathrm{~mL}$ screw cap tube containing $10 \mathrm{~mm}$ glass beads (Biospec products) in proteinase $\mathrm{K}$ buffer (10 mM Tris, pH8.0, $100 \mathrm{mM} \mathrm{NaCl}$, $10 \mathrm{mM}$ EDTA, 0.5\% SDS) and disrupted in an automated tissue homogenizer (Biddy Scientific, Stone, UK) for thirty seconds. The solution was transferred into a clean tube and $100 \mu \mathrm{g}$ proteinase K (Sigma-Aldrich) was 
added and incubated at $50{ }^{\circ} \mathrm{C}$ in a hybridization oven (Hybaid, Basingstoke, UK) with end over end rotation overnight or until tissue had dissolved. Samples were spun at $6000 \mathrm{rpm}$ in a table microfuge and the supernatant was transferred to a new tube. DNA was phenolchloroform extracted using standard protocols. Purified DNA was quantified and $1 \mu \mathrm{g}$ of DNA from each sample was serially diluted $1: 10$ and denatured in $0.4 \mathrm{M} \mathrm{NaOH}$ at $100{ }^{\circ} \mathrm{C}$ for $10 \mathrm{~min}$. Samples, neutralized with an equal volume of chilled Tris- $\mathrm{HCl}(\mathrm{pH}$ 6.8) were applied to a nitrocellulose membrane (GE Healthcare, Hatfield, UK). DNA was then hybridized by ultraviolet crosslinking in a UV stratalinker 1800 (Stratagene, Cambridge, UK) and the membrane was incubated at room temperature in 3\% non-fat Milk (Bio-Rad, Hemel Hempstead, UK) TBS-T containing either a 1:5000 dilution of anti$5 \mathrm{hmC}$ (Active Motif), 1:2000 dilution of anti-5mC (33D3, Diagenode) for two hours with shaking. Appropriate secondary antibodies (HRP conjugated donkey anti-rabbit or HRP conjugated donkey anti-mouse, Cell Signalling, Hitchin, UK) were diluted 1:5000 in 3\% non-fat Milk in TBS-Tween 20 and blots were incubated with agitation for one hour. Blots were visualized using ECL solution (Millipore, Watford, UK) and exposed to X-ray film (GE Healthcare).

\section{Quantitative reverse transcriptase real-time PCR (qRT-PCR) assay}

Bursal tissues were placed in RNA later (Qiagen, Manchester, UK) immediately after dissection. At the time of extraction, tissues were cut into a size that weighed $\sim 30 \mathrm{mg}$ and disrupted using glass beads (Biospec, Glasgow, UK) and an automated tissue homogenizer (Biddy Scientific). Lysates were spun through a QIAshredder (Qiagen) before RNA extraction using a RNeasy kit (Qiagen) and 500 ng of total RNA was reverse transcribed using superscript III (Life Technologies). One microliter of cDNA was mixed with platinum SYBR green reagent (Life Technologies) and used in a qRT-PCR assay, performed on an ABI 7900 96-well real-time thermocycler, to quantify relative amounts of cytosine modifying enzymes Tet 1 , Tet 2 and activation induced deaminase (AID) transcripts. Glyceraldehyde-3-phosphate dehydrogenase (GAPDH) was used as a reference gene and the $\Delta \Delta \mathrm{Ct}$ method of quantification was performed to obtain relative fold change to either embryonic day (ED) 16 bursa or from uninfected six-week old bursa. Primer sequences for AID (forward: CCTGCGTAACAAGATGGGTTGCCATGTG GAG and reverse: CGGGCAGTGAAAATGCGGAGGG TCAAGT) and Glyceraldehyde 3-phosphate dehydrogenase (GAPDH) (forward: GAAGCTTACTGGAATGGC TTTCC and reverse: CGGCAGGTCAGGTCAGGTCAA CAA) were published previously and validated to work efficiently in real time qPCR assays. Probes directed against chicken Tet 1 (forward: AAAAGGAAGCGCTGTGAG AA and reverse: CCACGCCAGTATGAGAATCA) and Tet2 (forward: CGGTCCTAATGTGGCAGCTA and reverse: TGCCTTCTTTCCCAGTGTAGA) were designed based on sequences from Ensembl (ENSGALG 00000004073.4 and ENSGALT00000017236 respectively). Statistical analysis, either a two way ANOVA followed by Bonferroni post hoc test or unpaired $t$-test were used to determine statistical significance between experimental groups using Prism 5 (Graphpad Software).

\section{Western blot}

Approximately twenty micrograms of tissue were cut into fragments and placed in $2.0 \mathrm{~mL}$ screw cap tube containing $10 \mathrm{~mm}$ glass beads (Biospec) in $500 \mu \mathrm{L}$ of RIPA buffer (Sigma) supplemented with protease inhibitors (Roche, Burgess Hill, UK) were disrupted using an automated tissue homogenizer (Biddy Scientific) for two thirty second pulses. Supernatant was transferred to a clean tube and spun at $14000 \mathrm{rpm}$ in a refrigerated table top microcentrifuge. Twenty microliters of the supernatant was run on a $12 \%$ SDS-PAGE gel and transferred to a nitrocellulose membrane (GE Healthcare) using a semi-dry transfer unit (Bio-Rad). The blot was blocked in 3\% non-fat milk at ambient temperature for one hour on a rotating shaker before incubation with an antibody directed to the IBDV capsid protein VP2 (generated by the microbiological services of The Pirbright Institute) in a 1:500 dilution overnight at $5{ }^{\circ} \mathrm{C}$ with gentle agitation. The blot was rinsed and a secondary HRP conjugated anti-mouse antibody (Sigma-Aldrich) was used at 1:10 000 dilution for one hour at room temperature before rinsing and visualization using ECL solution (Millipore) and exposure to X-ray film (GE Healthcare).

\section{Results}

Changes in $5 \mathrm{mC}, 5 \mathrm{hmC}$ and mRNAs of cytosine modifying enzymes during development of B-cells within the bursa of Fabricius

Using immunofluorescence we investigated potential changes in bursal $5 \mathrm{mC}$ and $5 \mathrm{hmC}$ genomic distribution at different embryonic and neonatal stages that encompass hallmarks of B-cell development. At embryonic day (ED) 16 , the bursa had a relatively uniform distribution of both $5 \mathrm{mC}$ and $5 \mathrm{hmC}$, although more intense $5 \mathrm{hmC}$ staining was consistently observed within the epithelial layers of the bursa (Figure 1A; arrows). This $5 \mathrm{hmC}$ enrichment becomes more apparent at successive stages of embryonic development when individual follicles can be definitively identified (dashed white outline) and become surrounded by a follicle associated epithelium (Figure 1A).

Associated with high $5 \mathrm{mC}$ levels in developing follicles (Figure 1A; dashed white outline) is a progressive 


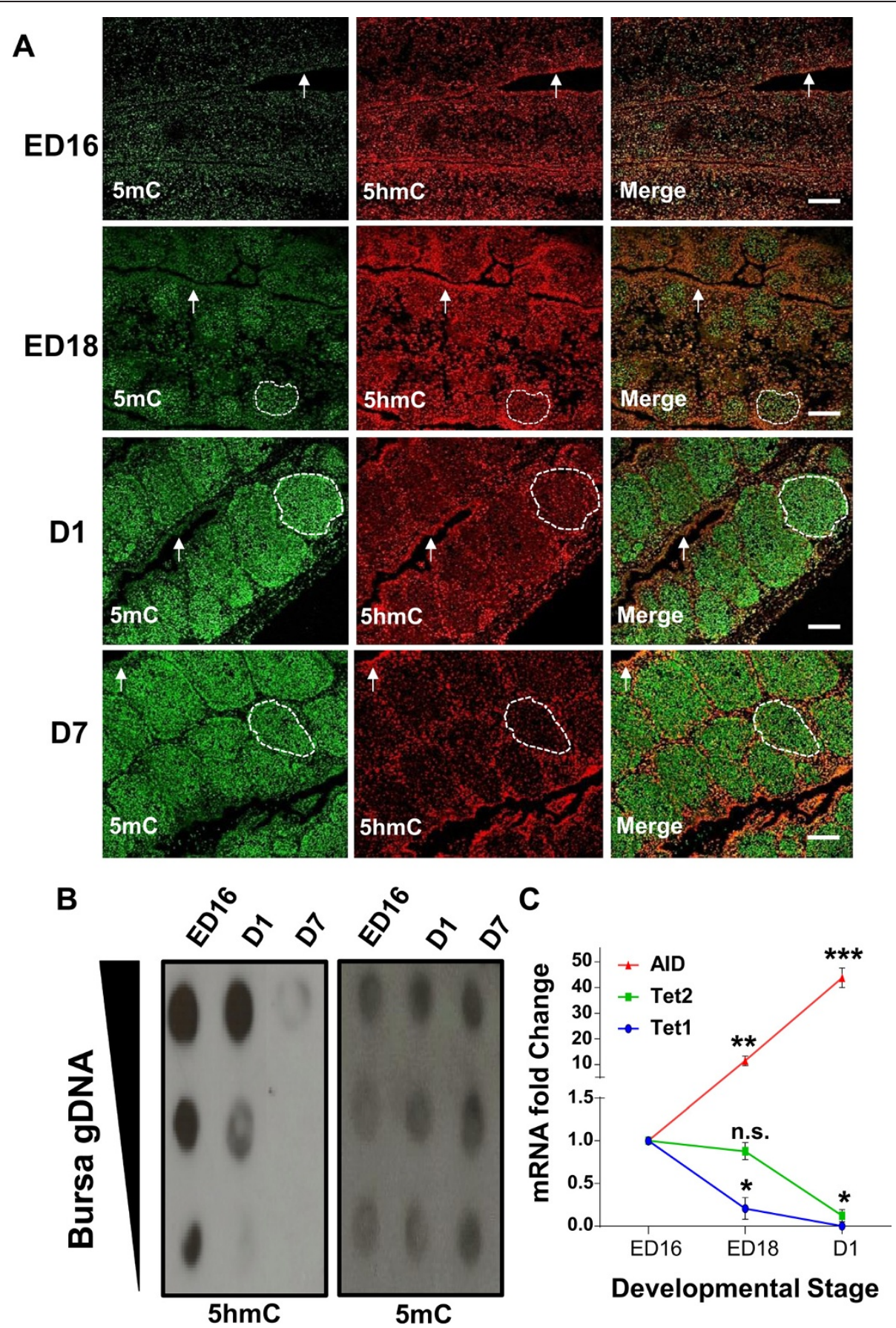

Figure 1 Changes in global $5 \mathrm{hmC}$ and $5 \mathrm{mC}$ levels and gene expression of cytosine modifying enzymes within the bursa of Fabricius during embryonic and neonatal development. A. Immunofluorescent staining of sections through embryonic day (ED) 16, ED18, one (D1) and seven days post hatch (D7) bursa of Fabricius. White dashed outlines delineate an individual follicle and arrows indicate epithelial structures. Scale bar $=100 \mu \mathrm{M}$. B. Dot blot assay using ten-fold dilutions of bursa genomic DNA from various developmental stages probed with an antibody directed to either $5 \mathrm{hmC}$ or $5 \mathrm{mC}$. C. Real time analysis of cytosine modifiying enzymes AID, Tet 1 and Tet 2 mRNA expression levels during the development of the bursa of Fabricus. n.s. $=$ non-significant, ${ }^{*} p<0.05,{ }^{* *} p<0.01$, ${ }^{* * *} p<0.005$ as determined by ANOVA and post-hoc tests. $n=4-5$ birds per group. 
developmental loss of $5 \mathrm{hmC}$ staining. This observed $5 \mathrm{hmC}$ reduction in bursal tissue sections was validated by a dot blot assay (Figure 1B) which shows a progressive reduction in genomic $5 \mathrm{hmC}$ from ED16 to seven days posthatch (D7). To confirm that the proliferating follicles did contain B-cells we co-stained ED18 bursal sections with $\mathrm{Bu}-1$, an avian B-cell marker [26], and either an antibody directed to $5 \mathrm{mC}$ or $5 \mathrm{hmC}$. We found that Bu-1 only stained cells within each follicle and the majority of these B-cells were also highly enriched for $5 \mathrm{mC}$ (Figure 2A). Furthermore, we observed that the B-cell genome contained relatively low levels of $5 \mathrm{hmC}$ compared to the surrounding bursal epithelial layers (Figure 2B).

With the increasingly $5 \mathrm{mC}$ enriched B-cell genome is the accumulation of bursal AID transcripts which increases approximately ten fold from ED16 to ED18 and forty fold from ED16 to one day post hatch (Figure 1C). While mRNA expression of both putative Tet 1 and 2 in the developing bursa significantly decreased from one day post hatch when compared to the bursa of ED16 chicks (Figure 1C).

\section{Effects of IBDV on $5 \mathrm{hmC}$ levels and Tet 1 and 2 mRNAs levels within infected bursa}

After hatch the bursa goes through a series of morphological changes which culminate in the formation of distinct cortical and medullary regions delineated by a basement membrane (BM) (Figure 3). We stained bursa from a six-week old chicken with antibodies to $\mathrm{Bu}-1$ and $5 \mathrm{hmC}$. We found that the majority of bursal cells were $\mathrm{Bu}-1$ positive (Figures 3 and $4 \mathrm{~A}$ ). Less intense staining for $\mathrm{Bu}-1$ was consistent with the location of the $\mathrm{BM}$ and bursal epithelium (BE), while $5 \mathrm{hmC}$ staining appeared more intense within cells that were not $\mathrm{Bu}-1$ positive such as within the $\mathrm{BM}$ and the $\mathrm{BE}$ (Figure 3).

Infection of six-week-old chickens with a dose of a virulent IBDV strain, UK661, caused a significant reduction in $\mathrm{Bu}-1$ staining within the bursa after $48 \mathrm{hpi}$ (Figure 4). Associated with this loss of Bu-1 was a global increase in immunostaining of $5 \mathrm{hmC}$ levels within the infected bursa when compared to uninfected, age-matched controls (Figure 4). Analysis of Tet 1 and 2 mRNAs by real time PCR revealed a significant increase in both transcripts within the bursa after IBDV infection (48 hpi) when compared to uninfected birds (Figure 5).

\section{Discussion}

Infectious bursal disease is a contagious viral induced inflammatory condition of economic and veterinary importance that effects commercial poultry flocks [23,24]. IBDV targets cells of the BF where the virus predominantly focuses on infecting actively proliferating and differentiating lymphocytes of the B-cell lineage of the chicken [25]. Reports have documented global genomic changes in methylation patterns, including the novel epigenetic mark $5 \mathrm{hmC}$, during both hallmarks of vertebrate
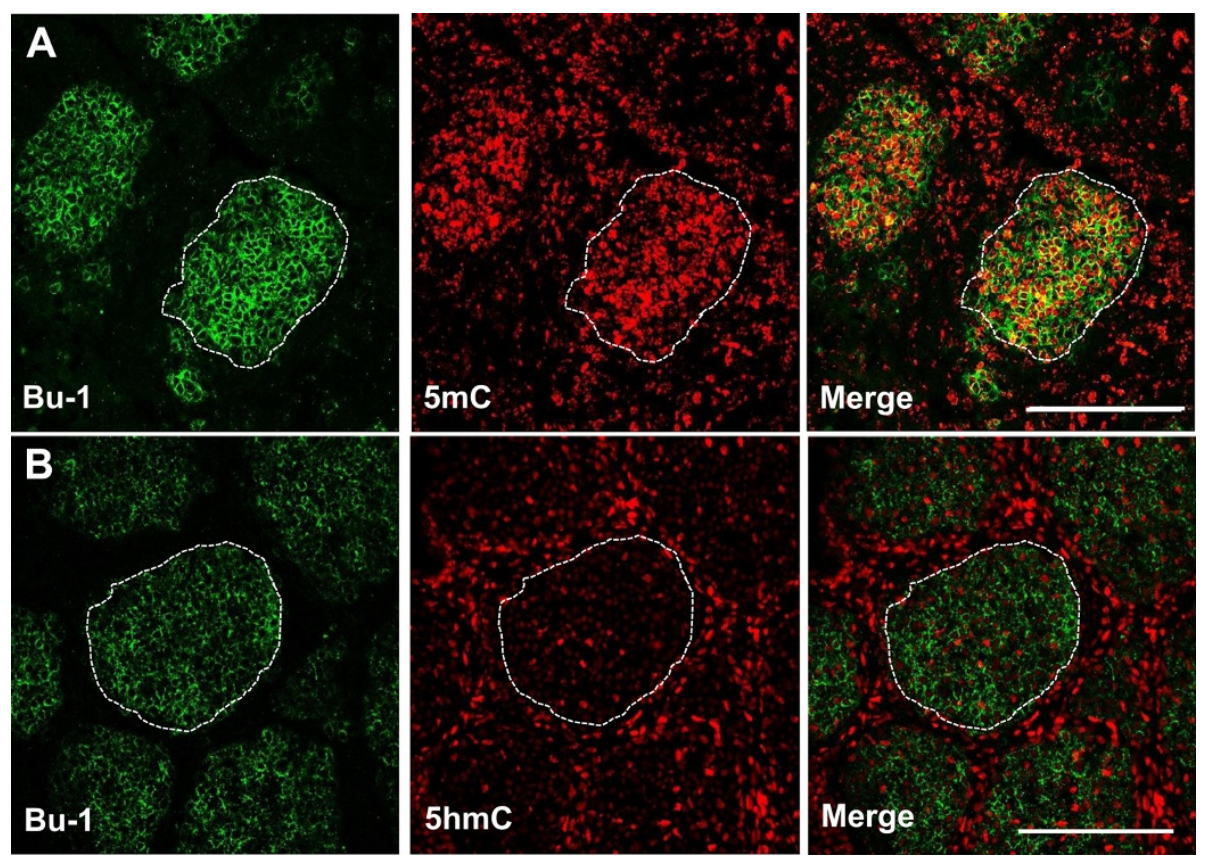

Figure 2 The distribution of $5 \mathrm{hmC}$ and $5 \mathrm{mC}$ relative to B-cell localisation within the embryonic bursa of Fabricius. Immunofluorescent staining of bursal sections of an embryonic day (ED) 18 chick showing the co-localisation of either A. $5 \mathrm{mC}$ or B. $5 \mathrm{hmC}$ with the avian B-cell marker, Bu-1. Dashed outlined area delineates a single B-cell containing bursal follicle. Bar $=100 \mu \mathrm{M}$. 

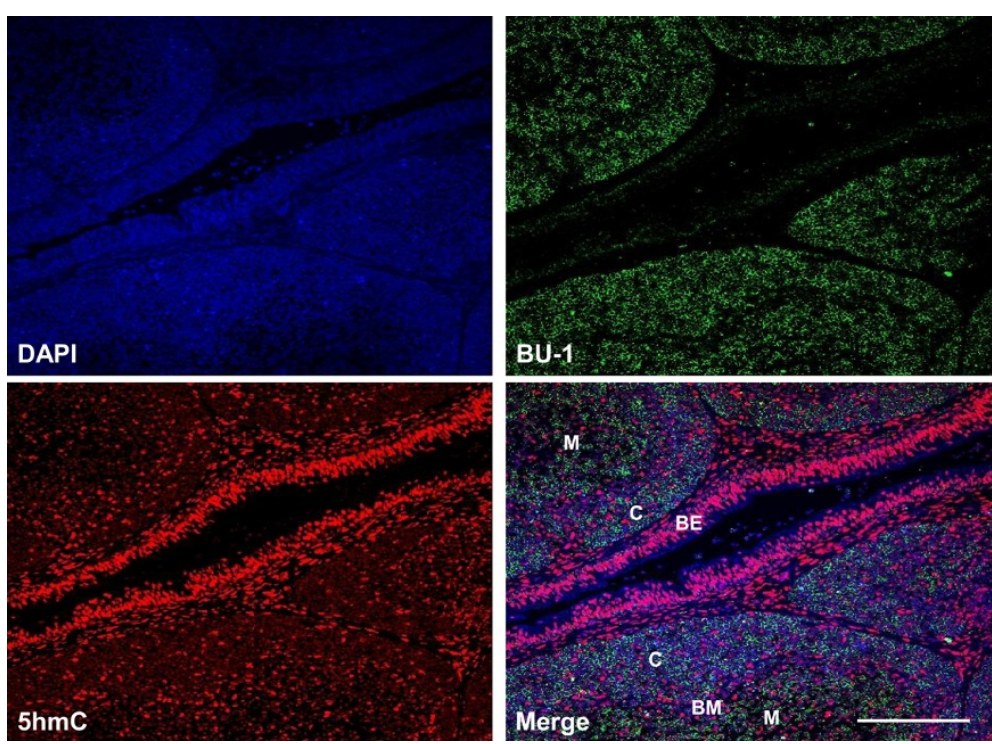

Figure 3 Evidence suggesting that $5 \mathrm{hmC}$ is enriched within bursal epithelia compared to B-cells. The bursa of a six week old chicken stained with $5 \mathrm{hmC}$ and the avian B-cell marker, Bu-1. DAPI used for counterstaining double stranded DNA. M = Medulla, C $=$ cortex, BE $=$ bursal epithelium, BM = basement membrane. Bar $=100 \mu \mathrm{M}$.

development [9] and the pathogenesis of cancers like leukaemia [15,16] and inflammatory diseases such as osteoarthritis [27]. In light of these findings, and given the predilection of IBDV for the BF, we investigated potential changes in genomic methylation during key stages of B-cell development and after IBDV infection.
Although the BF plays a critical role in avian B-cell development the commitment to the B-cell lineage occurs within embryonic hemopoietic stem cells outside this gut associated lymphoid organ [28]. The BF is subsequently colonized between eight and fourteen days of embryonic development by these prebursal stem cells where
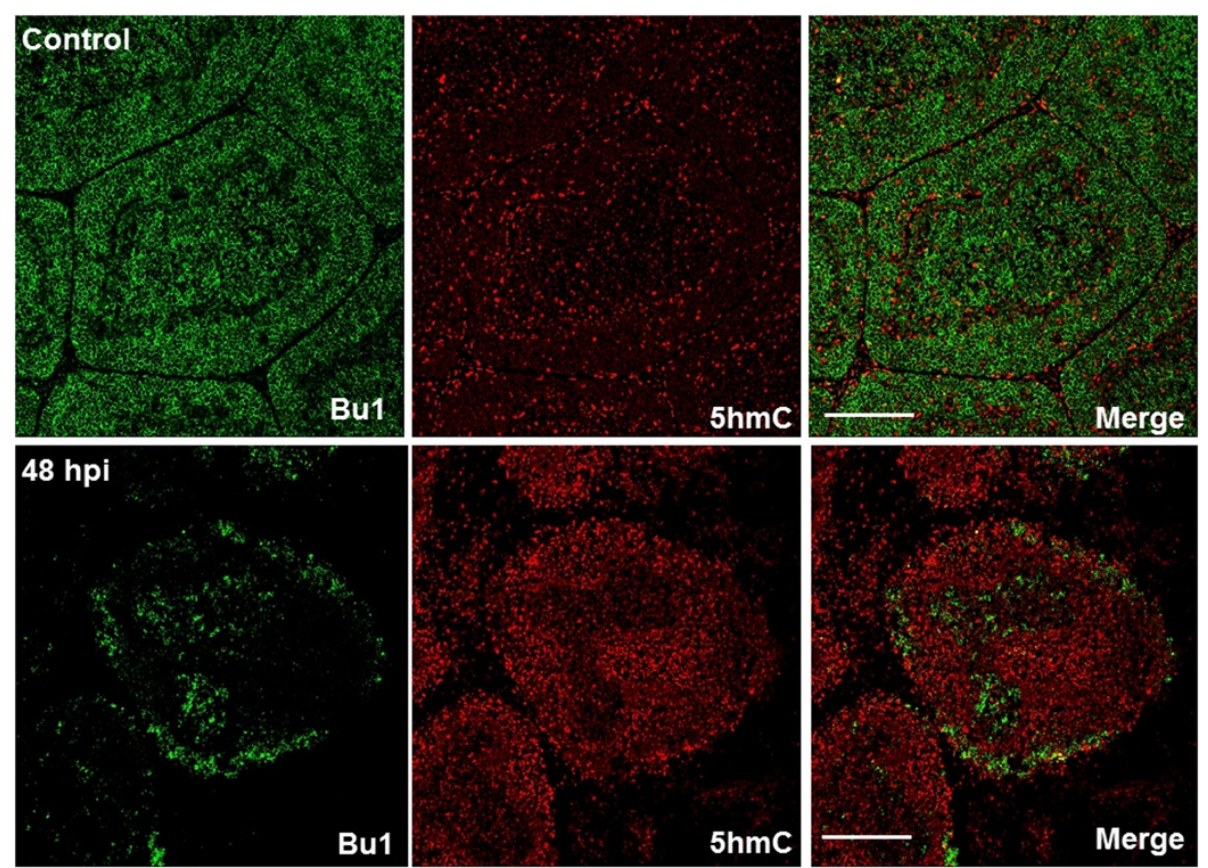

Figure 4 Changes in Bu-1 and $5 \mathrm{hmC}$ within the bursa of Fabricius between control and after IBDV infection. Immunofluorescent staining of bursal sections from either control or IBDV infected (48 hpi) 6-week old chickens showing co-localisation of $5 \mathrm{hmC}$ with the avian B-cell marker, Bu-1. $\mathrm{M}=$ Medulla; $\mathrm{C}=$ Cortex. Bar $=100 \mu \mathrm{M}$. 


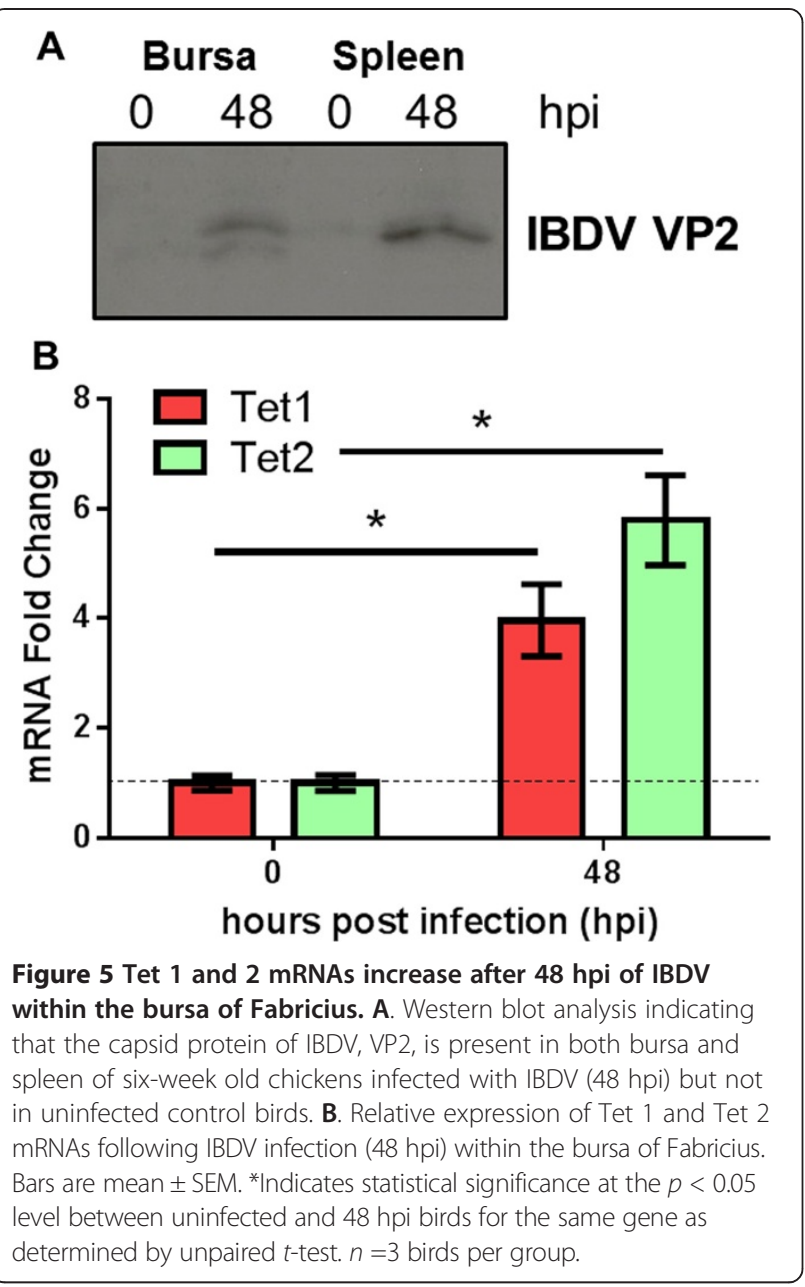

they expand extensively to form follicles [28]. Discernable follicle like structures could be determined by $5 \mathrm{mC}$ and $5 \mathrm{hmC}$ staining in bursal sections at around ED18 (Figure 1A). These follicles were enriched for $5 \mathrm{mC}$ staining when compared to the surrounding epithelium, a feature that is maintained through both embryonic and post hatch stages of BF development. We determined that these follicular cells were B-cells by co-staining with $\mathrm{Bu}-1$, an avian B-cell marker (Figure 2A). A possible reason for why developing B-cells have a predominantly high genomic $5 \mathrm{mC}$ level is due to the consequences of gene conversion, the process responsible for generating the primary antibody repertoire in the majority of vertebrates [29]. Gene conversion is dependent on the cytosine modifying enzyme activation-induced deaminase (AID) which generates antibody diversity at immunogloblin loci through targeted deamination of cytosines [29]. This process begins within the bursa at around ED18 [30,31] and the highly methylated B-cell genome may protect from the mutagenic activity of AID at off target sites as this enzyme is inefficient at deaminating $5 \mathrm{mC}$, particularly in the context of $\mathrm{CpG}$ motifs [32,33]. The observation that
AID is expressed in the bursa is consistent with both previous studies [34] and its involvement in antibody diversification by gene conversion in vivo, further supporting the notion that progressive methylation may protect the integrity of the B-cell genome from the increased expression of this deaminating enzyme (Figure $1 \mathrm{C}$ ). These findings coincide with the progressive decrease in bursal $5 \mathrm{hmC}$ levels, as measured by two independent techniques (Figure 1A and $\mathrm{B}$ ), and suggests that the reduction in Tet mRNA transcripts (Figure 1C) maybe causal to reduced genomic $5 \mathrm{hmC}$ within the developing BF. As mammalian Tet and AID proteins have been shown to interact [35] it is conceivable that Tet proteins may facilitate AID binding to genomic regions within B-cells. In this way, a developmental reduction in Tet 1 and 2 mRNAs may be part of a mechanism by which the B-cell genome is protected from the mutagenic activity of AID by reducing such interactions that could lead to off target genomic mutations.

As $\mathrm{Bu}-1$ is reduced considerably after IBDV infection within the BF (Figure 4) it remains unclear what cell type has elevated $5 \mathrm{hmC}$ within this tissue. It is possible that IBDV downregulates $\mathrm{Bu}-1$ expression in B-cells as is the case for reticuloendotheliosis virus T (V. Nair, unpublished observation), in this way, the increase in $5 \mathrm{hmC}$ may pertain to $\mathrm{Bu}-1$ negative $\mathrm{B}$-cells infected with IBDV in a mechanism that is likely to involve increased Tet 1 and 2 mRNAs (Figure 5B). After an IBDV infection macrophages and T-cells are known to infiltrate the $\mathrm{BF}[23,36]$ and it is conceivable that these immune cell types are contributing to the observed increase in bursal $5 \mathrm{hmC}$ levels and Tet 1 and 2 mRNAs. In support of this view is the finding that both activation of macrophages and T-cells causes genomic demethylation events which may include the involvement of elevated $5 \mathrm{hmC}$ levels and altered Tet function [37]. Furthermore, there is an emerging concept that pro-inflammatory cytokines may modulate Tet expression and $5 \mathrm{hmC}$ levels to cause transcriptional changes in cytokine responsive genes [27]. In this way, the release of cytokines from immune cells that have infiltrated the bursa may contribute to altered $5 \mathrm{hmC}$ levels observed in the current study and may be causal to genomic instability and subsequent cell death in B-cells. Alternatively, or in addition, elements of the bursal stromal network including the $\mathrm{BM}$ and $\mathrm{BE}$ (Figure 3) may also be responding to IBDV infection to mediate the documented changes within the $\mathrm{BF}$. The identity of which cell types are contributing to elevated $5 \mathrm{hmC}$ and Tet mRNA expression would be of interest and will form the bases for future studies.

In summary, we find that global $5 \mathrm{hmC}$ and $5 \mathrm{mC}$ genomic levels display temporal changes during the development of B-cells within the BF. Moreover, we show that the chicken embryonic B-cell has high levels of genomic methylation that may protect from the disruptive 
activity of the cytosine modifying enzyme, AID. IBDV infection causes immunosuppression through loss of B-cells and our data suggest that the underlying mechanisms may include disruption to genomic methylation patterns of the $\mathrm{BF}$ and an increase in global $5 \mathrm{hmC}$ genomic levels. This increase in $5 \mathrm{hmC}$ within infected host tissues may be part of a hitherto unrecognised mechanism by which a virus can cause genomic instability and cell death to facilitate viral egress.

\section{Abbreviations}

5hmC: 5-hydroxymethylcytosine; 5mC: 5-methylcytosine; AID: Activationinduced deaminase; Tet: Ten-11 translocation; hpi: Hours post infection; ED: Embryonic day; IBDV: Infectious bursal disease virus; BF: Bursa of Fabricius; BM: Basement membrane; BE: Basement epithelium.

\section{Competing interests}

The authors declare that they have no competing interests.

\section{Authors' contributions}

NAC conceptual idea of the study, participated in its design and coordination and drafted the manuscript, WM participated in its design and critically reviewed and amended the manuscript, AR participated in its design and technical aspects of the study and critically reviewed and amended the manuscript, LPS participated in its design and critically reviewed and amended the manuscript, CB participated in its design and critically reviewed and amended the manuscript, $\mathrm{VN}$ critically reviewed and amended the manuscript. All authors read and approved the final manuscript.

\section{Acknowledgements}

We are grateful to Lydia Kgosana, Lawrence Petherbridge and Claire Powers for help with animal experiments. This work was funded by the Biotechnology and Biological Sciences Research Council (BBSRC) through The Pirbright Institute fellowship scheme awarded to NAC.

\section{Author details}

${ }^{1}$ Avian Viral Diseases (AVD), Compton Laboratory, The Pirbright Institute, Compton, Berkshire RG20 7NN, UK. ${ }^{2}$ Wolfson Centre for Stem Cells, Tissue Engineering and Modelling (STEM), Division of Cancer and Stem Cells, School of Medicine, Centre for Biomolecular Sciences, University of Nottingham, University Park, Nottingham NG7 2RD, UK.

Received: 22 July 2014 Accepted: 7 October 2014

Published online: 23 October 2014

\section{References}

1. Law JA, Jacobsen SE: Establishing, maintaining and modifying DNA methylation patterns in plants and animals. Nat Rev Genet 2010, 11:204-220.

2. Jaenisch R, Bird A: Epigenetic regulation of gene expression: how the genome integrates intrinsic and environmental signals. Nat Genet 2003, 33(Suppl):245-254.

3. Tahiliani M, Koh KP, Shen Y, Pastor WA, Bandukwala H, Brudno Y, Agarwal S, lyer LM, Liu DR, Aravind L, Rao A: Conversion of 5-methylcytosine to 5-hydroxymethylcytosine in mammalian DNA by MLL partner TET1. science 2009, 324:930-935.

4. Ito S, D'Alessio AC, Taranova OV, Hong K, Sowers LC, Zhang Y: Role of Tet proteins in $5 \mathrm{mC}$ to $5 \mathrm{hmC}$ conversion, ES-cell self-renewal and inner cell mass specification. Nature 2010, 466:1129-1133

5. Ito S, Shen L, Dai Q, Wu SC, Collins LB, Swenberg JA, He C, Zhang Y: Tet proteins can convert 5-methylcytosine to 5-formylcytosine and 5-carboxylcytosine. Science 2011, 333:1300-1303.

6. Nestor CE, Ottaviano R, Reddington J, Sproul D, Reinhardt D, Dunican D, Katz E, Dixon JM, Harrison DJ, Meehan RR: Tissue type is a major modifier of the 5-hydroxymethylcytosine content of human genes. Genome Res 2012, 22:467-477.

7. Li W, Liu M: Distribution of 5-hydroxymethylcytosine in different human tissues. J Nucleic Acids 2011, 2011:870726.
8. Koh KP, Yabuuchi A, Rao S, Huang Y, Cunniff K, Nardone J, Laiho A, Tahiliani M, Sommer CA, Mostoslavsky G, Lahesmaa R, Orkin SH, Rodig SJ, Daley GQ Rao A: Tet 1 and Tet2 regulate 5 -hydroxymethylcytosine production and cell lineage specification in mouse embryonic stem cells. Cell Stem Cell 2011, 8:200-213.

9. Almeida RD, Loose M, Sottile V, Matsa E, Denning C, Young L, Johnson AD, Gering M, Ruzov A: 5-hydroxymethyl-cytosine enrichment of noncommitted cells is not a universal feature of vertebrate development. Epigenetics 2012, 7:383-389.

10. Almeida RD, Sottile $V$, Loose $M$, De Sousa PA, Johnson AD, Ruzov A: Semi-quantitative immunohistochemical detection of 5-hydroxymethylcytosine reveals conservation of its tissue distribution between amphibians and mammals. Epigenetics 2012, 7:137-140.

11. Stroud H, Feng S, Morey Kinney S, Pradhan S, Jacobsen SE: 5Hydroxymethylcytosine is associated with enhancers and gene bodies in human embryonic stem cells. Genome Biol 2011, 12:R54.

12. Chen $\mathrm{H}$, Dzitoyeva $\mathrm{S}$, Manev $\mathrm{H}$ : Effect of aging on 5hydroxymethylcytosine in the mouse hippocampus. Restor Neurol Neurosci 2012, 30:237-245.

13. Coppieters N, Dieriks BV, Lill C, Faull RL, Curtis MA, Dragunow M: Global changes in DNA methylation and hydroxymethylation in Alzheimer's disease human brain. Neurobiol Aging 2014, 35:1334-1344.

14. Pfeifer GP, Kadam S, Jin SG: 5-hydroxymethylcytosine and its potential roles in development and cancer. Epigenetics Chromatin 2013, 6:10.

15. Ko M, Rao A: TET2: epigenetic safeguard for HSC. Blood 2011, 118:4501-4503.

16. Ko M, Bandukwala HS, An J, Lamperti ED, Thompson EC, Hastie R, Tsangaratou A, Rajewsky K, Koralov SB, Rao A: Ten-Eleven-Translocation 2 (TET2) negatively regulates homeostasis and differentiation of hematopoietic stem cells in mice. Proc Natl Acad Sci U S A 2011, 108:14566-14571.

17. Seo SY, Kim EO, Jang KL: Epstein-Barr virus latent membrane protein 1 suppresses the growth-inhibitory effect of retinoic acid by inhibiting retinoic acid receptor-beta2 expression via DNA methylation. Cancer Lett 2008, 270:66-76.

18. Tsai CN, Tsai CL, Tse KP, Chang HY, Chang YS: The Epstein-Barr virus oncogene product, latent membrane protein 1, induces the downregulation of E-cadherin gene expression via activation of DNA methyltransferases. Proc Natl Acad Sci U S A 2002, 99:10084-10089.

19. Arora $P$, Kim EO, Jung JK, Jang KL: Hepatitis $C$ virus core protein downregulates E-cadherin expression via activation of DNA methyltransferase 1 and 3b. Cancer Lett 2008, 261:244-252.

20. Laurson J, Khan S, Chung R, Cross K, Raj K: Epigenetic repression of E-cadherin by human papillomavirus 16 E7 protein. Carcinogenesis 2010, 31:918-926.

21. Davison TF: The immunologists' debt to the chicken. Br Poult Sci 2003, 44:6-21.

22. Baaten BJ, Staines KA, Smith LP, Skinner H, Davison TF, Butter C: Early replication in pulmonary $B$ cells after infection with Marek's disease herpesvirus by the respiratory route. Viral Immunol 2009, 22:431-444.

23. Sharma JM, Kim IJ, Rautenschlein S, Yeh HY: Infectious bursal disease virus of chickens: pathogenesis and immunosuppression. Dev Comp Immunol 2000, 24:223-235.

24. van den Berg TP, Eterradossi N, Toquin D, Meulemans G: Infectious bursal disease (Gumboro disease). Rev Sci Tech 2000, 19:509-543.

25. Rodenberg J, Sharma JM, Belzer SW, Nordgren RM, Naqi S: Flow cytometric analysis of B cell and T cell subpopulations in specific-pathogen-free chickens infected with infectious bursal disease virus. Avian Dis 1994, 38:16-21.

26. Tregaskes CA, Bumstead N, Davison TF, Young JR: Chicken B-cell marker chB6 (Bu-1) is a highly glycosylated protein of unique structure. Immunogenetics 1996, 44:212-217.

27. Taylor SE, Smeriglio P, Dhulipala L, Rath M, Bhutani N: A global increase in 5-hydroxymethylcytosine levels marks osteoarthritic chondrocytes. Arthritis Rheumatol 2014, 66:90-100

28. Ratcliffe MJ, Lassila O, Pink JR, Vainio O: Avian B cell precursors: surface immunoglobulin expression is an early, possibly bursa-independent event. Eur J Immunol 1986, 16:129-133.

29. Arakawa H, Buerstedde JM: Immunoglobulin gene conversion: insights from bursal B cells and the DT40 cell line. Dev Dyn 2004 229:458-464 
30. Reynaud CA, Anquez V, Grimal H, Weill JC: A hyperconversion mechanism generates the chicken light chain preimmune repertoire. Cell 1987, 48:379-388

31. Masteller EL, Lee KP, Carlson LM, Thompson CB: Expression of sialyl Lewis $(x)$ and Lewis $(x)$ defines distinct stages of chicken $B$ cell maturation. J Immunol 1995, 155:5550-5556.

32. Wijesinghe P, Bhagwat AS: Efficient deamination of 5-methylcytosines in DNA by human APOBEC3A, but not by AID or APOBEC3G. Nucleic Acids Res 2012, 40:9206-9217.

33. Larijani M, Frieder D, Sonbuchner TM, Bransteitter R, Goodman MF, Bouhassira EE, Scharff MD, Martin A: Methylation protects cytidines from AID-mediated deamination. Mol Immunol 2005, 42:599-604.

34. Withers DR, Davison TF, Young JR: Developmentally programmed expression of AID in chicken B cells. Dev Comp Immunol 2005, 29:651-662.

35. Arioka Y, Watanabe A, Saito K, Yamada Y: Activation-induced cytidine deaminase alters the subcellular localization of Tet family proteins. PLOS One 2012, 7:e45031.

36. Rauf A, Khatri M, Murgia MV, Jung K, Saif YM: Differential modulation of cytokine, chemokine and Toll like receptor expression in chickens infected with classical and variant infectious bursal disease virus. Vet Res 2011, 42:85.

37. Suarez-Alvarez B, Rodriguez RM, Fraga MF, Lopez-Larrea C: DNA methylation: a promising landscape for immune system-related diseases. Trends Genet 2012, 28:506-514.

doi:10.1186/s13567-014-0108-5

Cite this article as: Ciccone et al:: A B-cell targeting virus disrupts potentially protective genomic methylation patterns in lymphoid tissue by increasing global 5-hydroxymethylcytosine levels. Veterinary Research 2014 45:108

\section{Submit your next manuscript to BioMed Central and take full advantage of:}

- Convenient online submission

- Thorough peer review

- No space constraints or color figure charges

- Immediate publication on acceptance

- Inclusion in PubMed, CAS, Scopus and Google Scholar

- Research which is freely available for redistribution 